\title{
GIS BASED MULTI-PARAMETER OPTIMAL PATH ANALYSIS FOR RURAL SCHOOLS
}

\author{
D. K. Meena ${ }^{1, *}$, R. Tripathi ${ }^{2}$, S. Agrawal $^{3}$ \\ ${ }^{1}$ GIS Cell, Motilal Nehru National Institute of Technology Allahabad, Prayagraj -211004, Uttar Pradesh, India, \\ dmeena@mnnit.ac.in \\ ${ }^{2}$ Department of Electronics \& Communication Engineering, Motilal Nehru National Institute of Technology Allahabad, Prayagraj - \\ 211004, Uttar Pradesh, India, rt@mnnit.ac.in \\ ${ }^{3}$ GIS Cell, Motilal Nehru National Institute of Technology Allahabad, Prayagraj -211004, Uttar Pradesh, India, sonam@mnnit.ac.in
}

Commission V, WG V/7 \& Commission IV, WG IV/6

KEY WORDS: Multi-parameter decision analysis, Optimal path, Geographic Information System (GIS), Spatial

\begin{abstract}
:
Using the Geographic Information System (GIS) technology, transportation and network analysis has become a straightforward application. An underlying problem in transportation and network analysis is to find optimal paths between different locations from sources to destination on a network. Sometimes this optimal path between source to destination has to be done in real-time. Several optimal path algorithms have been proposed by the researchers based on single parameter problem. In this paper, a multi-parameters based optimal path solution is proposed using GIS software for the travelling of children to schools. For these rural schools of Bara tehsil of Prayagraj district in India is selected. Three different parameters are taken to find the optimal path which is population density-based, travelling distance-based and travelling time-based optimal path. The developed optimum path is the least cost and satisfied by the other technical, environmental, economic and social criteria. This paper provides a solution if the government need to apply any policy that needs to visit each school. This paper will help the government in land management. On the basis of this paper, government can find schools which are not connected with road and can plan a new road to connect each school by road.
\end{abstract}

\section{INTRODUCTION}

Transportation is an essential aspect of child education. Most of the time there are several paths to reach the school. Selection of optimal path for transportation is the major issue for parents to send their children to school. The cost involved in transportation is a concern of the lower and middle-income group parents. Sometimes it hampers the child education that results in absenteeism and in worse case school dropout (Aggarwal, 2018). GIS can provide solutions that can help to reduce this problem.

GIS is can be defined as "a decision support system involving the integration of spatially referenced data in a problem solving environment" (Cowen, 1988).GIS can be used to develop a model that determines the optimal path for transportation (Ghose et al., 2006). It can be used as a decision support tool by students and school vehicle drivers to find the optimal path from sources to the destination (Singh et al., 2019). Using the multiple parameters based optimal path, the fastest route for a student to go and come from his home location to school location can be determined. This optimal path also can be followed by the school's bus drivers to receive students from their home location and drop out at the school using best optimal path. Based on the literature review there are many algorithms to find the optimal path (Pettit et al., 2018).

In this paper, the use of GIS is demonstrated in the identification of optimal path. The objective of the paper is to find the optimal path on the basis of population density, travelling distance and travelling time. As compared to shortest path application, multi-parameters based optimal path for rural schools of Bara tehsil using GIS software is more helpful. The database for Bara tehsil rural schools has been prepared and using GIS software optimal path from source to destination has been identified from the prepared database. Using GIS software the optimal path is to be calculated and the results were displayed. The user can view the optimal path based on these parameters. On the basis of travelling purpose user can choose the best paths. Many times the government wants to apply some policy that involves the visiting or surveying each school. This paper also provides a solution to this problem. Travel Salesmen Problem (TSP) is applied to find the optimal sequence to visit all schools. This also helps to identify whether there is road connectivity available or not.

\section{STUDY AREA}

Prayagraj district is in Uttar Pradesh state of India. It has been divided into eight tehsils, which are further divided into twenty developmental blocks. They are further divided into 1426 gram panchayat and then into 3095 revenue villages (Internet-1 2019). In all tehsils, except Prayagraj city, literacy rate is less than $60 \%$. In Bara tehsil literacy rate is just $56.22 \%$. As per Census of India (2011), there are 160,067 illiterate persons in Bara. This tehsil needs special attention to promote and support the literacy works. Therefore, Bara tehsil is selected as the study area.

\footnotetext{
* Corresponding author
} 


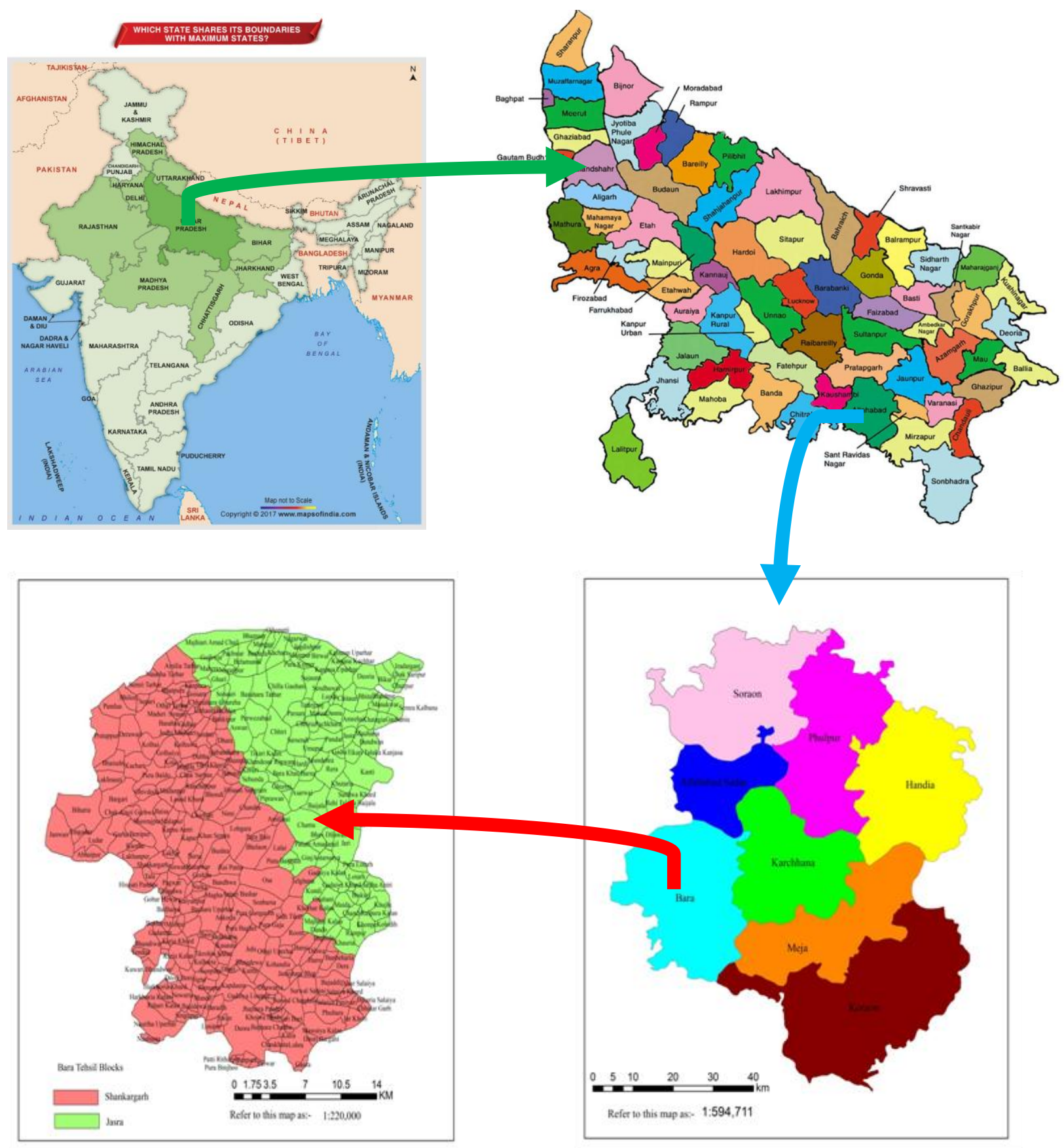

Figure 1. Bara tehsil location map

Bara tehsil's geographical extent is from $81.525^{\circ} \mathrm{N}, 25.029^{0} \mathrm{E}$ to $81.859^{0} \mathrm{~N}, 25.357^{0} \mathrm{E}$. It is divided into two developmental blocks, namely Shankargarh and Jasra. These two blocks are further disvided into 326 revenue villages.

\section{TITLE AND ABSTRACT BLOCK}

This paper aims to identify multi-parameters based optimal path for rural schools. It highlights the potential use of GIS in the representation of available optimal path from source to destination. This optimal path will help the people living in rural area to find the best path to send their child in school and to return them to home in safely and timely manner. The methodology followed for this work is shown in Figure 2. This involves the creation of a GIS database of schools and road networks. Each of the school is located on the map along with road network connectivity.

\section{DATA REQUIREMENT AND SOURCES OF DATA}

The following data is required for this work.

\subsection{School Location Data}

There are 476 schools in Bara tehsil. Location of 476 schools is collected by field surveying. Minimum four satellites are required in GPS to calculate the $(x, y, z, t)$, i.e. longitude, latitude elevation of any place and time. The Trimble Juno 3B series handheld GPS is used for field survey to find the exact location 


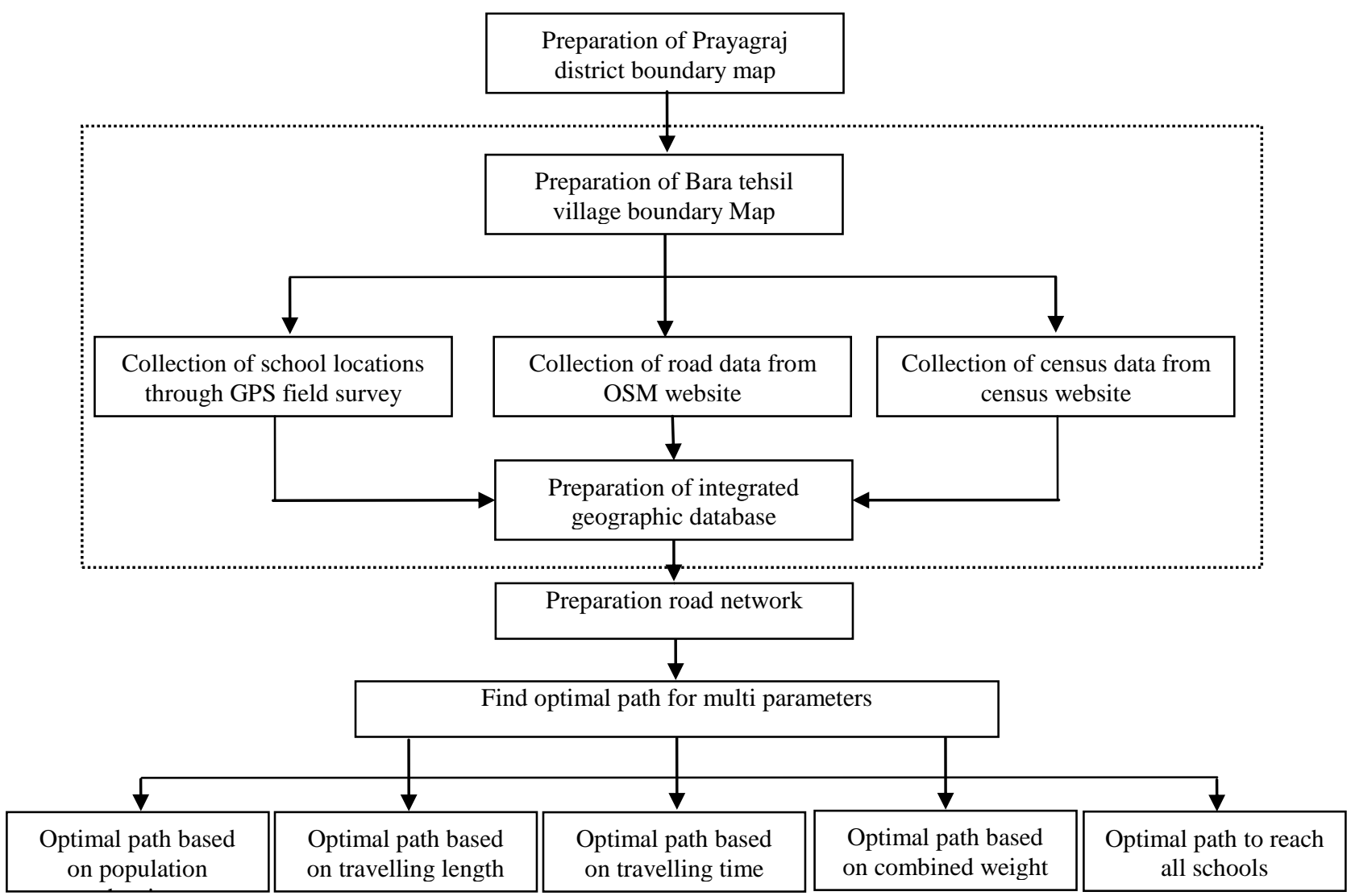

Figure 2. Methodology flow chart

of the schools. TerraSync software setup has been used in the Trimble Juno series 3B handheld GPS receivers. For the GPS field survey, TerraSync software is opened after the receiver is started. After doing all the necessary steps, the number of visible satellites is checked to ensure accuracy. This is done in the software by using the Skyplot screen of Status section. After the required accuracy is achieved the position is collected. All the school locations are collected in this way.

After the collection of data through GPS, data are transfer in Trimble field data (.SSF) format. When the data are transferred in .SSF format successfully then it is exported or converted into the ESRI point shapefile by using the GPS Pathfinder Office 5.60 software. Map in Figure 3 is showing the collected Bara tehsil schools which are overlayed on the village boundary layer.

Accuracy of the location collected by GPS field survey depends upon the accuracy of GPS instrument. The accuracy of the hand held GPS used in this survey work is 3 - 5 meters. Therefore, collected location may be displaced by this range. This minor displacement does not affect the output of this work. In the raw data only school and village name is given. During the survey, it was very difficult to find the school. With the help of local people each of the school is searched and surveyed.

\subsection{Boundary Data}

Boundary data is collected from maps. Prayagraj tehsil boundary map is generated from the Survey of India topographical maps. The toposheet number $63 \mathrm{G}, 63 \mathrm{H}, 63 \mathrm{~K}$ and $63 \mathrm{~L}$ are used to prepare Prayagraj tehsil boundary map. The scale of these maps is 1:2,50,000. These maps are first

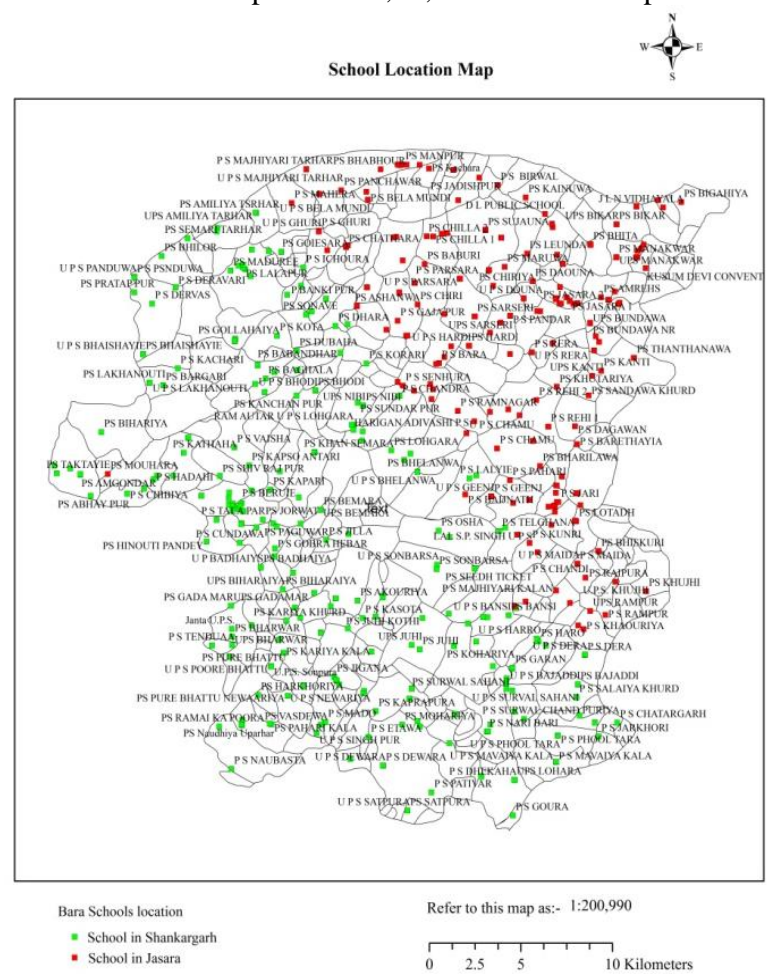

Figure 3. Bara tehsil schools location map 


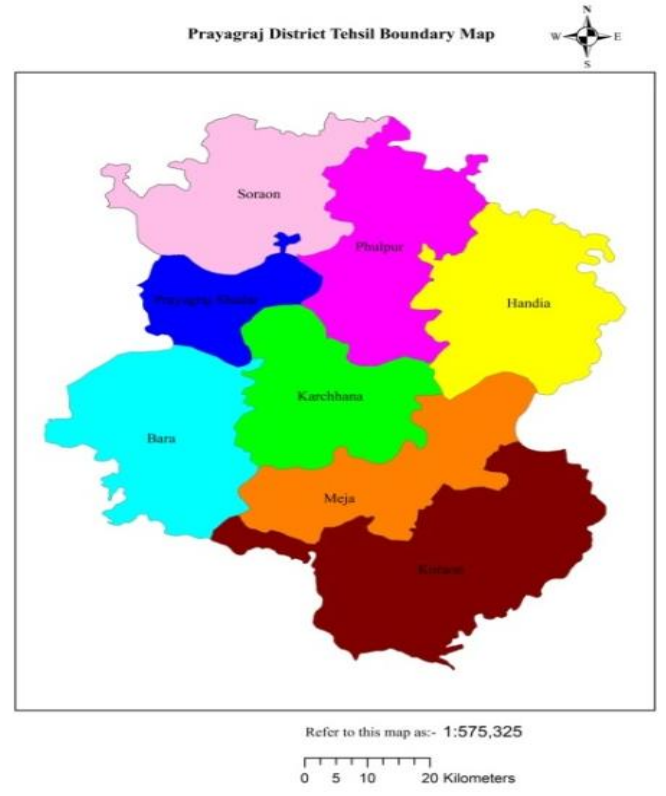

Figure 4. Prayagraj district tehsil boundary map

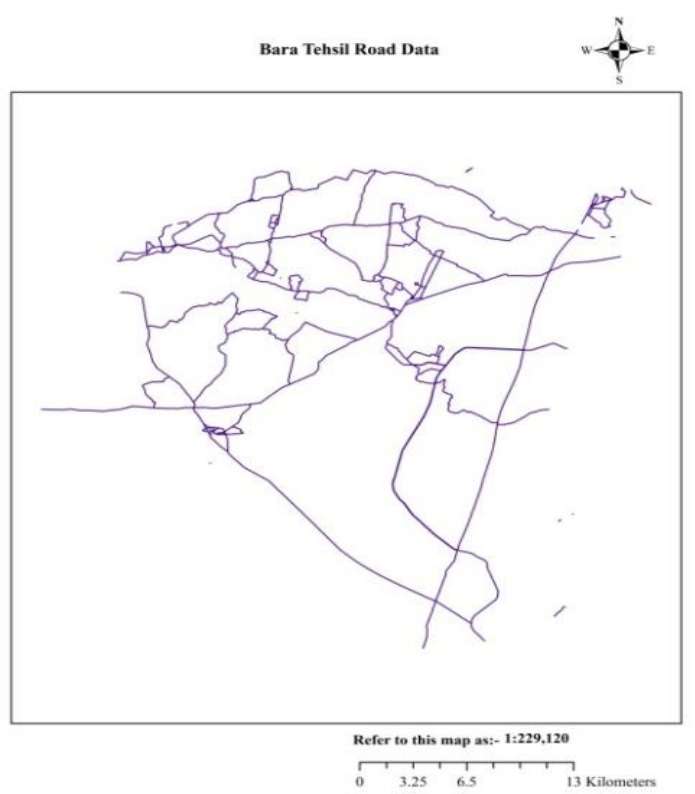

Figure 6. Bara tehsil road map

georeferenced and then mosaiced. After this tehsil boundary of Prayagraj district is extracted by digitizing this mosaiced map. This digitized tehsil boundary map is shown in Figure 4. Bara village boundary map is prepared from NIC map. Bara tehsil village map is then georeferenced and digitized by using ArcGIS software. This village boundary map is shown in Figure 5 .

\subsection{Census Data}

Population data of each village is collected from the census website of the year 2011. There are ninety six parameters in population data. Out of these parameters, nine parameters are used in this paper which are village name, village code, block name, total population, total male population, total female population, total literate population, literate male population

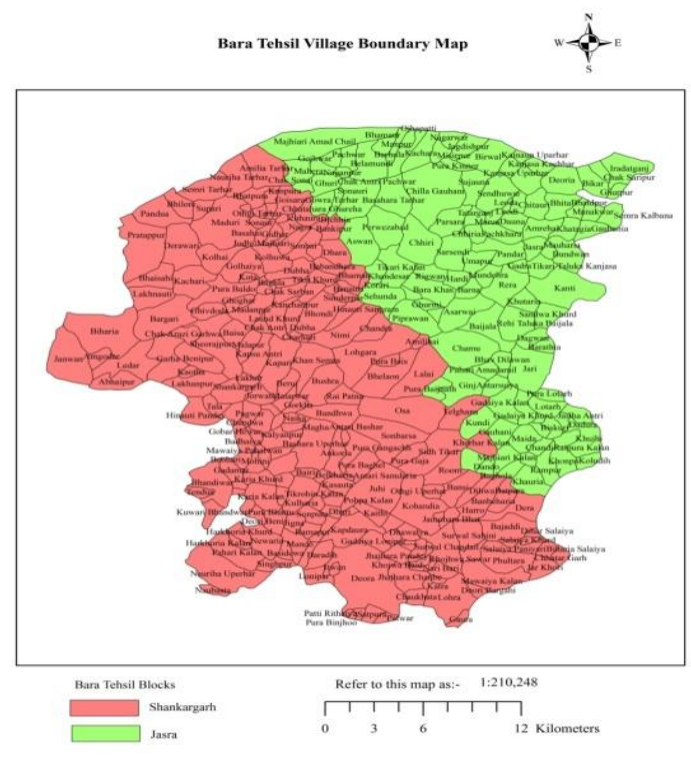

Figure 5. Bara tehsil village boundary map



Figure 7. Bara tehsil road network map

and literate female population. Based on these parameters, attribute table of the village boundary layer is prepared.

\subsection{Road Data}

Road data of Bara tehsil is downloaded from OpenStreetMap (OSM) website (https://download.bbbike.org/osm/extract/ planet_80.08,24.38_83.56,26.57.osm.shp.zip). This data is in shapefile format. The datum of this data is WGS 84 . The spatial data type of this road is polyline. The road map is shown in Figure 6.

For the optimal path analysis, there is a need to assign the weight to the road data based on population. Therefore, splitting of road data is performed according to the village boundary. After splitting the road data with village boundary, village 




Figure 8. Bara tehsil school location map with road connectivity

population data is added in road shapefile attribute table. For the optimal path analysis, this polyline needs to convert into a network data type. This conversation is performed using ArcGIS software. The road network map is shown in Figure 7 where line is showing the road edge and point is showing the junction.

\subsection{Bara Tehsil School Location with Road Network}

In Figure 8, Bara tehsil village school location map is shown with village boundary and road networks connectivity. In this map, points are showing the school location and lines are showing the road network of Bara tehsil. From this map, it can be seen that in the rural area most of the schools are not connected with road.

\section{LEAST COST OPTIMAL PATH}

To apply the shortest path algorithm on road networks weight is need to be assigned. For this purpose literature review is performed. On the basis of this review, several parameters required for the optimal path as identified like travel time, travel distance, toll on route, quantitative information, qualitative information, number of turns, weather, time of day, congestion, safety, directness and comfort (Bowen and Ciyun, 2015 ; Li and Leung, 2011; Musliman, Rahman, and Coors, 2007; Papinski and Scott, 2011). However, in a rural area, some of these parameters are not required. To find optimal path from source to destination three parameters are selected which are population density, travelling distance and travelling time. Population density affects the traffic than any other factors. In rural area, many children go to school on foot so travelling distance becomes very important factor to find optimal path. Since the study area lies in a rural region, therefore travelling distance is selected as one of the parameter. Every student and their parents want to spend minimum time in commuting. Therefore, travelling time is chosen as one of the parameter. Hence, based



Figure 9. Bara tehsil population density map

on these three parameters combined weights are defined to find optimal path.

\subsection{Population Density}

To calculate population density (PD), first of all, the area of each village is calculated. For this calculate geometry tool is used which adds the area value in the attribute table of village boundary layer. In village boundary map attribute table, population data of year 2011 is added by joining the MS Excel file which is obtained from the census website. Using the following PD formula population density of each village is calculated in number of peoples in per $\mathrm{km}^{2}$ area.

\section{$\mathrm{PD}=$ Total Population of Village / Total area of Village}

Bara tehsil population density map is shown in Figure 9. This population density data is classified into five categories. Based on population density, the average speed limit in kilometer per hour is assumed as shown in Table 1.

\begin{tabular}{|l|l|l|}
\hline S. No. & $\begin{array}{l}\text { Population Density } \\
\text { (peoples in per } \mathrm{km}^{2}\end{array}$ & $\begin{array}{l}\text { Average speed } \\
\text { (km per hour) }\end{array}$ \\
\hline 1. & $0-200$ & 60 \\
\hline 2 & $201-400$ & 50 \\
\hline 3 & $401-600$ & 40 \\
\hline 4 & $601-1000$ & 30 \\
\hline 5 & Above 1000 & 20 \\
\hline
\end{tabular}

Table 1. Average speed based on population density

A new attribute is added with the road layer to assign it a weight as per the population density. For this road layer, which is in shapefile format, is split by village boundary layer using the split tool of ArcGIS. After this population density attribute is added with each road based on the village in which it is falling. 


\subsection{Travel Distance}

Travel distance is also taken as the weights that need to be added in the road attribute table. The coordinate reference system of road data is the geographic coordinate system. The datum of this data is WGS 84. To calculate travelling length, road data is converted from geographic coordinate system (GCS) to projected coordinate system (PCS) using ArcGIS Software. Then using calculates geometry tool of ArcGIS travel length of each road of Bara tehsils is calculated.

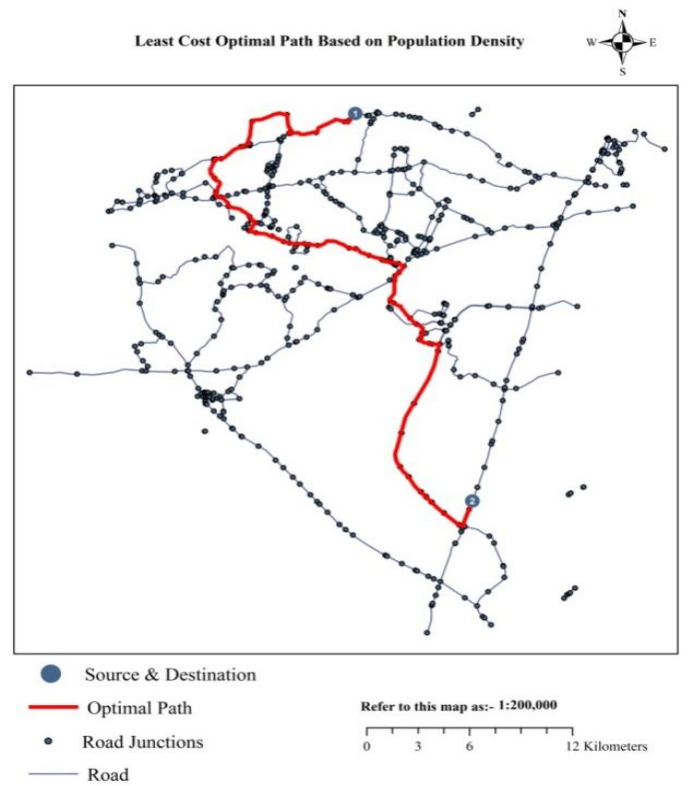

Figure 10. Optimal path map based on population density

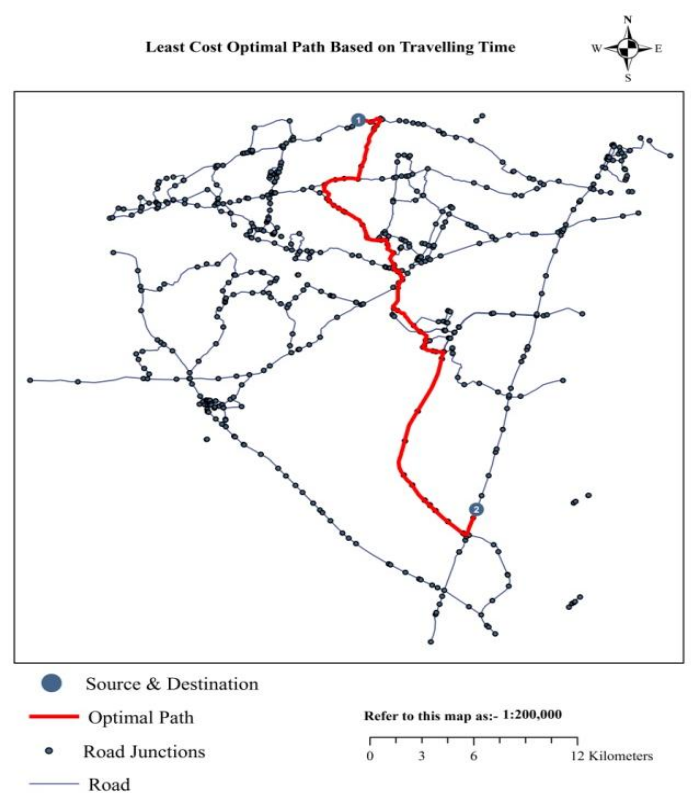

Figure 12. Optimal path based on travelling time map

\subsection{Travel Time}

A new field is added in the attribute table by using following travelling time (TT) calculation formula.

\section{TT= Travelling Distance $/$ Average speed}

Travelling distance is calculated in the previous section. The average speed of the vehicle is assumed based on population density of the village through which road is passing.

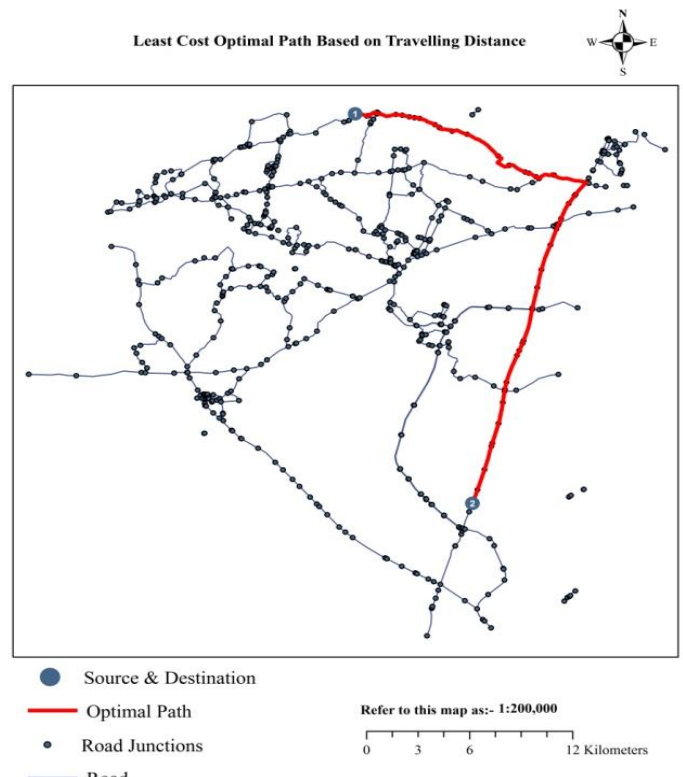

Figure 11. Optimal path map based on travelling distance



Figure 13. Optimal path based on combine weight map 


\subsection{Combined Weight}

To calculate the optimal path based on above parameters a combine equation is defined. Because traffic is dependent mostly on population density so it is multiplied by three and then on travelling distance, so it is multiplied by two. Traffic in a rural area is affected very less by travelling time other than population density and travelling distance. So it will be same as actual travelling time. The following equation calculates combined weight:

$$
\text { Combined weight }=(3 * \mathrm{PD}+2 * \mathrm{TD}+1 * \mathrm{TT}) / 6
$$

where

PD - Population Density in number of people in per square kilometer

TD- Travelling Distance in meters

TT- Travelling Time in seconds

Using the above equation combined weight is calculated. The attribute table is prepared for these parameters. Using networks analysis tool in ArcGIS, Bara tehsil road network is prepared. Using the new route tool in ArcGIS optimal path from source to destination is identified based on each parameter.

\subsection{Travel Salesman Problem (TSP)}

To visit all the schools starting from a particular point and then return to that particular location in order to find that there is road available or not TSP is used. Given a set of schools, distance, time and population density weight between every pair of school the TSP can find the least cost shortest possible route that visits every school exactly once and returns to the starting point. TPS helps to find that the road available or not available to reach a particular school.

\section{RESULTS AND DISCUSSION}

Using the above three parameters combine weight has been calculated and the attribute table of the above-mentioned parameters has been prepared. This attribute table data is a combination of school location data, village boundary data and census data of Bara tehsil. Road networks connectivity with school and find optimal path from source home location to destination school location and return from destination school location to source home location also identified. The different optimal path for the same source location and same destination location have been identified based on population density, travelling distance and travelling time which is shown in Figure 10, Figure 11 and Figure 12 respectively. Another map based on the combined map is also prepared which is shown in Figure 13 .

Figure 14 is showing the output of TSP which is applied to the Bara tehsil schools. The points in red color are those schools that are not reachable by road. There are 36 schools in Bara tehsil villages which have no road facility and unable to reach by road. Therefore, based on the TSP problem, new routes required to connect every school of Bara tehsil from road can be identified through this analysis.

\section{CONCLUSION}

In the present paper, spatial analysis on the reachability of schools is performed. A spatial database is built that contains

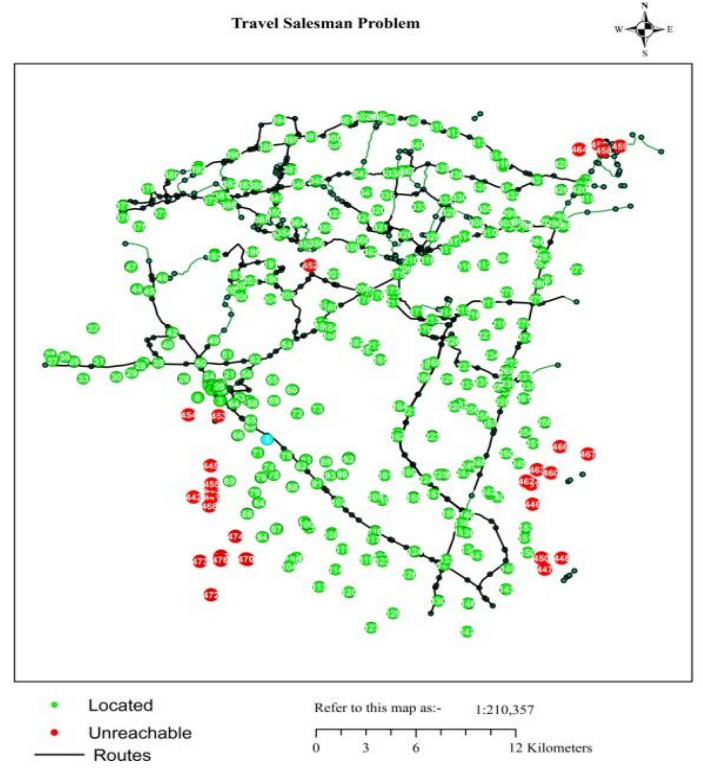

Figure 14. Optimal path based on travelling time map

the school and road data of Bara tehsil. Optimal path analysis has been performed based on three parameters, i.e. population density, travelling distance and travelling time. A combined weight function is also given to find the optimal path. Many times there is a requirement to reach all the schools to distribute the food or any other material. This paper also gave the optimal route to visit all the schools by using the travelling salesman problem. This work will help the people to select the best possible path based upon their requirement. This paper will support the land administrators in planning. This paper will also help the government in the identification of locations where new roads need to be constructed so that every school will have the road connectivity.

\section{REFERENCES}

Aggarwal, S., 2018. Do rural roads create pathways out of poverty? Evidence from India. J. Dev. Econ. 133, 375-395. https://doi.org/10.1016/j.jdeveco.2018.01.004

Bowen, G., Ciyun, L., 2015. A Personalized Urban Multicriteria Shortest Path Stochastic Optimization Algorithm. Math. Probl. Eng. 2015, 1-8. https://doi.org/10.1155/2015/987358

Cowen, D.J., 1988. GIS versus CAD versus DBMS: what are the differences? Photogramm. Eng. Remote Sensing 54, 15511555 .

Ghose, M.K., Dikshit, A.K., Sharma, S.K., 2006. A GIS based transportation model for solid waste disposal - A case study on Asansol municipality. Waste Manag. 26, 1287-1293. https://doi.org/10.1016/j.wasman.2005.09.022

Li, R., Leung, Y., 2011. Multi-objective route planning for dangerous goods using compromise programming. J. Geogr. Syst. 13(3), 249-271. https://doi.org/10.1007/s10109-0100124-6 
Musliman, I.A., Rahman, A.A., Coors, V., 2007. Implementing 3D Network Analysis in 3D-GIS. Int. Arch. Photogramm. Remote Sens. Spatial Inf. Sci., XXXVII-2/W4, 913-918.

Papinski, D., Scott, D.M., 2011. A GIS-based toolkit for route choice analysis. J. Transp. Geogr. 19(3), 434-442. https://doi.org/10.1016/j.jtrangeo.2010.09.009

Pettit, C., Bakelmun, A., Lieske, S.N., Glackin, S., Hargroves, K. 'Charlie,' Thomson, G., Shearer, H., Dia, H., Newman, P., 2018. Planning support systems for smart cities. City, Cult. Soc. 12, 13-24. https://doi.org/10.1016/j.ccs.2017.10.002

Singh, P., Singh, A.K., Singh, P., Kumari, S., Sangaiah, A.K., 2019. Multimodal data modeling for efficiency assessment of social priority based urban bus route transportation system using GIS and data envelopment analysis. Multimed. Tools Appl. 78(17), 23897-23915. https://doi.org/10.1007/s11042018-6147-6

Internet-1: http://vlist.in/district/175.html (Accessed on 17 April 2019) 